\title{
ENTRE O ESTADO, A SOCIEDADE E O MERCADO: análise dos dispositivos de governança da indústria florestal na Amazônia
}

\author{
Marcelo Domingos Sampaio Carneiro*
}

\begin{abstract}
A discussão sobre os instrumentos mais eficazes para enfrentar e corrigir os problemas ambientais opõe duas formas básicas de regulação: de um lado, as ações baseadas na iniciativa estatal, denominadas "comando e controle", e, de outro, as realizadas por intermédio de mecanismos de mercado e por iniciativas autônomas de limitação das ações, baseadas no civismo, como no caso dos códigos de boa conduta adotados por várias empresas. No presente artigo, discutimos três desses diferentes dispositivos de regulação da indústria florestal na Amazônia - a certificação florestal, o modelo das florestas familiares e a política de concessões florestais -, procurando destacar suas principais diferenças, com base em uma tipologia das formas gerais de coordenação das atividades econômicas proposta por Boyer (2004), enriquecida por um aporte da economia das convenções, que classifica o tipo de coordenação entre atores segundo a natureza da convenção constitutiva predominante.

PALAVRAS-CHAVE: indústria florestal, governança, políticas públicas, sociologia econômica.
\end{abstract}

\section{INTRODUÇÃO}

Este artigo tem por objetivo expor os termos do debate contemporâneo sobre a melhor forma de realizar a regulação da exploração dos recursos naturais em regiões de florestas tropicais, tomando para análise o caso dos dispositivos ${ }^{1}$ elaborados para promover a governança da exploração florestal na Amazônia brasileira.

Com esse objetivo, realizo um mapeamento das principais propostas elaboradas por agências governamentais e organizações não governamentais (ONGs) envolvidas na promoção de políticas florestais na Amazônia brasileira (Buclet, 2002,

* Doutor em Sociologia. Professor do Programa de Pósgraduação em Ciências Sociais da Universidade Federal do Maranhão.

Avenida dos portugueses s/n. Bacanga. Cep: 65000-000. São Luis - Maranhão - Brasil. mdscarneiro@uol.com.br

${ }^{1}$ Utilizo o conceito de dispositivo de forma semelhante à elaborada por alguns autores da nova sociologia econômica, isto é, como um conjunto de elementos que possibilitam a realização da troca mercantil (Beuscart; Peerbaye, 2006). Nessa perspectiva, o conceito de dispositivo substitui parcialmente o de instituição, ao tratar de fenômenos que garantem o funcionamento de certos tipos de mercados, sem ter, contudo, o alcance (globalidade verticalidade e coerência) daquele (Karpik, 2007).
2009; Carneiro, 2011), apresentando suas principais características, como são expostas por seus defensores, para, em seguida, submetê-las à crítica. Ou seja, procuro ler essas proposições como uma elaboração indígena dos produtores de políticas florestais (experts florestais, organizações não governamentais, instituições estatais), para, em seguida, confrontá-las com uma análise das formas de coordenação das atividades econômicas, tal como ela tem sido desenvolvida pela sociologia econômica, com base nas contribuições de duas correntes da sociologia econômica francesa (teoria da regulação e economia das convenções).

Realizo esse exercício a partir da construção de uma tipologia das formas de coordenação das atividades econômicas (Boyer, 2004). Por meio dessa tipologia, procuro identificar as diferentes formas de governança da atividade florestal segundo dois critérios: i) a natureza (horizontal ou vertical) das formas de coordenação entre os agentes que participam da exploração florestal e ii) a motivação que orienta a atuação desses agentes, considerando a distinção operada pela economia das convenções entre preço e qualidade (Eymard- 
Duvernay, 1995; 2003; Salais; Storper, 1993). ${ }^{2}$

Acredito que a utilização dessa tipologia permite uma melhor compreensão da natureza dos dispositivos de governança em questão, destacando aspectos que as disputas entre seus defensores - a batalha dos experts florestais nos termos de Smouts (2001) - tendem a obscurecer, contribuindo, dessa forma, para clarificar o debate sobre as formas de governança de recursos naturais.

O debate sobre as diferentes propostas de regulação da exploraçãodas florestas tropicais (Gueneau; Tozzi, 2008) parece-me um campo extremamenteapropriado para a discussão das formas de governança de recursos naturais, uma vez que se trata de um tema complexo, envolvendo uma multiplicidade de atores públicos e privados, situados em diferentes espaços (local, nacional eglobal) (Smouts, 2001), aomesmotempo em que dialoga com uma ampla diversidade de políticas públicas (fundiária, creditícia, ambiental, etc.), as quais, em tese, deveriam articular-se para produzir resultados setoriais e territoriais (Carneiro, 2011).

O artigo está organizado em quatro seções. Na primeira, apresento o debate sobre a questão da governança da exploração dos recursos naturais, destacando a oposição entre formas de regulação dirigidas pelo mercado e dirigidas pelo Estado. Na segunda seção, exponho os principais dispositivos elaborados para enfrentar a questão da exploração predatória da floresta amazônica e promover o manejo florestal sustentável, caso da certificação florestal (Carneiro, 2004, 2007), das florestas familiares (Amaral Neto; Carneiro; Miranda, 2011; Lima et al., 2003) e da política de concessões florestais (Carneiro, 2011; Drigo, 2010). Na terceira seção, introduzo a tipologia para a análise desses dispositivos de governança da exploração florestal, para, na última seção, finalizar o texto com um balanço dos resultados obtidos por cada um desses dispositivos, apontando algumas tendências para o desenvolvimento das formas de governança da indústria florestal na Amazônia.

As relações entre a teoria da regulação e a economia das convenções apresentam pontos de convergência e de dissenso, conforme exposto por Robert Boyer (2006) e Olivier Faverau (2002). Para os objetivos deste artigo, basta sublinhar que essas duas abordagens consideram a questão da coordenação das atividades econômicas uma das questões centrais a ser investigada pelas ciências sociais.

\section{OS DIFERENTES USOS DO CONCEITO DE GOVERNANÇA}

O debate sobre os mecanismos de governança da gestão dos recursos florestais aparece como o produto da crise dos instrumentos tradicionais do Estado para garantir o cumprimento das políticas públicas. Podemos dizer, portanto, que a apresentação de propostas como a da certificação florestal (Carneiro, 2007), dos arranjos entre empresas e comunidades (Lima et al., 2003) e do manejo de florestas ${ }^{3}$ por comunidades (Amaral; Amaral Neto, 2000) insere-se num contexto mais amplo da crítica da incapacidade do Estado para fazer valer sua autoridade sobre a sociedade, ${ }^{4}$ ou para responder às diferentes demandas que emergem da sociedade civil no contexto de uma economia cada vez mais globalizada (Le Galés, 1995).

A apresentação do conceito de governança, neste primeiro momento, pode ser associada ao movimento mais amplo de crítica da capacidade estatal de enfrentar o desafio da gestão das demandas sociais, por meio da recuperação de uma discussão realizada no âmbito da teoria da firma (Le Galés, 1998). Nesse sentido, ele pode ser associado ao de boa governança, como orientação de agências multilaterais (BIRD, OCDE, FMI), ou ao de governança despolitizada, como estratégia política para fazer frente à aliança entre políticos e burocratas na produção de políticas públicas (Jobert, 2003).

Contudo, existe outra forma de apresentar o debate sobre o conceito de governança, no qual esse conceito aparece como uma resposta mais adequa${ }^{3}$ Em uma definição simplificada, o manejo florestal é descrito como "a administração de uma floresta para a obtenção de benefícios econômicos e sociais, respeitando-se os mecanismos de sustentação do ecossistema" (Silva, 2001, p.15). Para que essa administração seja realizada, são utilizados princípios técnicos estabelecidos pela silvicultura, que é o ramo da ciência florestal que define os parâmetros para o estabelecimento, a condução e a colheita de árvores.

${ }^{4}$ Dezalay (2007) analisa, para o caso europeu, a passagem de uma política ambiental comunitária centrada na atuação de comando e controle do Estado-policial (étatgendarme) para uma regulação negociada entre empresários, burocracia comunitária e ONG. Essa interpretação pode também ser considerada como uma leitura do pano de fundo da passagem de uma política ambiental centrada na regulação estatal para outra, fundada na governança de multiatores, proposta a partir da experiência holandesa de concertação entre agências governamentais e industriais. 
da a um tipo de intervenção pública envolvendo diferentes atores sociais, entre os quais o Estado, cujo objetivo é o estabelecimento da coordenação de diferentes atores em uma determinada questão (Commaille; Jobert, 1998). Nesse caso, a noção de governança traduz-se em diferentes "formas de coordenação que associam atores públicos com atores privados, pertencentes ao mundo das empresas e/ ou sociedade civil, para fazer frente a um problema complexo caracterizado por uma multiplicidade de atores e de escalas de intervenção" (Baron, 2003).

Portanto, podemos opor uma ideia de governança (ou boa governança) de teor normativo, em que predominam lógicas mercantis para a resolução de problemas antes cativos da ação pública, a uma abordagem que vê a governança como uma forma de coordenação policêntrica, associando, em geometria variável, atores oriundos do Estado, da iniciativa privada e da sociedade civil. Na análise aqui apresentada, a noção de governança tem esse último sentido, como a tentativa de construção de políticas governamentais num contexto em que o Estado não detém mais o primado da ação pública (Le Galès, 1998), ou não possui mais a capacidade e os recursos necessários para operacionalizar suas ações de forma vertical (Borrraz, 2004).

No caso específico da exploração de recursos naturais, uma forma eficiente de governança seria aquela capaz de fazer frente aos desafios suscitados por problemas ambientais, o que implica lidar com a) uma regulação econômica que ultrapassa as fronteiras do Estado-nação, b) a necessidade de articulação supranacional, c) a utilização de instrumentos complementares aos disponíveis para a ação estatal e d) a existência de uma articulação de multiatores, mais adaptada à resolução de problemas complexos (Micheletti, 2004).

\section{AS DIFERENTES PROPOSTAS PARA A GOVERNANÇA DA ATIVIDADE FLORESTAL NA AMAZÔNIA}

\section{A certificação florestal na Amazônia brasileira}

A proposta de certificação das atividades da indústria florestal é uma tentativa de resolver o problema da exploração florestal predatória por meio da incitação de empresas a adotarem práticas sustentáveis de manejo florestal. Essa incitação concretiza-se por meio do aumento do preço pago pela madeira manejada e do acesso privilegiado a mercados consumidores mais exigentes (caso, principalmente, do mercado da Europa ocidental) (Carneiro, 2007; CEE; FAO, 2009).

Para ter acesso ao selo florestal, a empresa deve submeter-se a um processo de avaliação realizado por uma terceira parte (uma organização certificadora), que, com base no caderno de obrigações do selo em questão, avalia a qualidade (social, ambiental e econômica) do manejo florestal realizado pela empresa avaliada. Destarte, podemos dizer que esse seloéuma convenção de qualidade (Eymard-Duvernay, 1995) que atesta que o bem ou o serviço oriundo de uma determinada empresa é produzido segundo critérios ambientais, sociais e econômicos que se aproximam das condições de sustentabilidade.

Dois momentos são fundamentais para o funcionamento dessa convenção de qualidade: a elaboração do caderno de encargos (os Princípios e Critérios do Forest Stewardship Council (FSC)) e a operacionalização do processo de certificação. No primeiro caso, temos o processo de elaboração da norma específica que será utilizada para avaliar a operação de manejo florestal (Carneiro, 2007), enquanto, no segundo momento, temos a própria operação do dispositivo de certificação, quando o processo de atribuição do selo florestal é efetuado, começando pela avaliação da empresa por uma organização certificadora.

Um atributo importante para o estabelecimento da legitimidade ${ }^{5}$ da construção do selo, como dispositivo que promete promover a adoção de práticas sustentáveis de exploração florestal, é a afirmação de sua imparcialidade relativa (Cochoy, 2002), isto é, de sua capacidade de representar os diversos interesses presentes na atividade florestal sem iden-

${ }^{5}$ A discussão sobre a legitimidade aqui sugerida está relacionada com a proposta feita por Boltanski (1990) de tratar essa questão no âmbito da relação entre atores sociais. Essa visão é retomada por Orléan (2004), para a análise das relações entre agentes econômicos sobre a qualidade um bem (ou serviço). 
tificar-se com qualquer um deles em particular.

Portanto, um selo florestal, como no caso de qualquer convenção de qualidade, é objeto de disputas e negociações, devendo esse certificado ser o resultado de um acordo justificado (Boltanski; Thévenot, 1991), cuja referência central é a negociação de um compromisso com uma noção de sustentabilidade (social, econômica e ambiental) da exploração florestal. Essa negociação sobre a qualidade do produto florestal, da forma como ele foi produzido, é fundamental para a compreensão do funcionamento do mercado de madeiras certificadas. Nessa perspectiva, o intercâmbio de um produto certificado ocorre de forma semelhante ao destacado pela economia das convenções:

A difusão de um produto passa por uma série de negociações com atores que se busca envolver ou impedir a defecção. De forma diferente da abordagem econômica tradicional nós consideramos que essas negociações não concernem somente ao preço de troca, a qualidade do produto é também negociada. [...] O preço de mercado constitui uma dessas referências: um vendedor argumentará sobre a validade de sua oferta se referindo ao preço de mercado. Ao mesmo tempo, ele se apoiará no renome de sua marca ou sobre o respeito de certos padrões (standards) para justificar a qualidade (Eynard-Duvernay, 1995, p.45).

Existem dois sistemas de certificação florestal implantados no Brasil: o Forest Stewardship Council (FSC), cuja origem remonta ao início dos anos 1990, e o Programa Brasileiro de Certificação Florestal (CERFLOR), que também foi lançado nos anos 1990, mas só se tornou operacional no início do presente século (Carneiro, 2012). No que concerne à certificação de florestas na Amazônia brasileira, o FSC é o selo predominante, contando, até o final de 2010, com vinte e três empreendimentos certificados, dos quais dezoito estão voltados para a produção madeireira (Pereira et al., 2010).

Em outra oportunidade (Carneiro, 2011), destaquei a evolução e as principais tendências do movimento de certificação florestal na Amazônia brasileira. Nessa avaliação, sublinhei que, depois de um início tímido, concentrado em empresas nos estados do Pará e Amazonas, a certificação diversificou-se, atingindo outros estados, com des- taque para o Acre, que é o único estado da região a possuir uma política de desenvolvimento baseada na exploração e no beneficiamento de produtos florestais (Adeodato et al., 2011). Contudo, apesar do aumento do número de operações certificadas, o incremento da certificação de florestas naturais, na Amazônia brasileira, tem ocorrido num ritmo bastante lento, e um número importante de empresas - sete operações florestais até julho de 2010 - perdeu ou cancelou suas operações certificadas.

Essa redução no ritmo de operações certificadas pode ser explicada também pela expectativa gerada entre os empresários do setor florestal pela aprovação da Lei de Gestão das Florestas Públicas (LGFP) (Lei n. ${ }^{0} 11.284$, de 2 de março de 2006) e pelo início do processo efetivo de licitação das áreas para exploração das florestas públicas por meio do mecanismo de concessão (Carneiro, 2011; Drigo, 2010).

\section{Os acordos entre empresas e comunidades por meio da proposta das florestas familiares}

Os estudos sobre a constituição de assentamentos de reforma agrária e o deslocamento de frentes de expansão camponesas na Amazônia mostram que esses processos possuem forte relação com o desenvolvimento da atividade madeireira. Para os madeireiros, essa abertura da floresta para a implantação de atividades agrícolas gera um volume elevado de matéria-prima florestal, enquanto, para os agricultores, a presença desses agentes da exploração madeireira fornece recursos (para a abertura de estradas, para o abastecimento de água, etc.) que eles teriam dificuldade em mobilizar.

Em período mais recente, organizações de representação de agricultores familiares, de empresários madeireiros e organizações não governamentais passaram a discutir formas mais elaboradas desse tipo de relação, procurando inseri-la nos marcos da legislação ambiental vigente e procurando minimizar seus aspectos mais assimétricos. No caso específico das regiões central e oeste do estado do Pará, esse debate ganhou relevo com a apresentação das propostas de articulação de em- 
presas e agricultores familiares em torno da iniciativa de aproveitamento da madeira autorizada para o desmatamento em projetos de assentamentos (PA), intitulada Safra Legal ${ }^{6}$ (Gomes, 2005), e da proposta de formalização de acordos entre empresas e comunidades para a realização de manejo florestal, conhecida como Florestas Familiares, ou o modelo Manejo Florestal e Prestação de Serviços (MAFLOPS) (Lima et al., 2003; NEPSTAD et al., 2005).

Essas duas iniciativas podem ser consideradas como uma reação de atores da sociedade civil regional ao aumento da fiscalização ambiental na indústria madeireira levada a cabo pelo Instituto Brasileiro do Meio Ambiente e Recursos Naturais Renováveis (IBAMA) no ano de 2003, que deixou clara a situação de ilegalidade em que funcionavam os polos madeireiros localizados na região da rodovia Transamazônica.

Para fazer frente a essa questão, entidades de representação dos movimentos sociais na região, apoiadas por organizações não governamentais, como a Fundação Viver Produzir e Preservar (FVPP), o Instituto de Pesquisas da Amazônia (IPAM) e o Instituto Seiva, elaboraram propostas que procuravam articular dois objetivos: i) garantir uma oferta legal de matéria-prima para a indústria madeireira e ii) ampliar os benefícios (diretos e indiretos) recebidos por agricultores familiares quando da venda de madeira de seus lotes.

A proposta das florestas familiares foi teoricamente formalizada por uma publicação do IPAM, que descreveu esse arranjo produtivo a partir da observação da atuação da empresa Manejo Florestal e Prestação de Serviços (MAFLOPS), na região do município de Santarém (PA), da seguinte forma:

No modelo de produção madeireira em propriedades de pequenos produtores, aqui definida como Florestas Familiares, a empresa madeireira investe na regularização fundiária, na infraestrutura e no planejamento do manejo florestal na propriedade do agricultor e na comunidade agrícola. [...] O modelo desenvolvido pela

${ }^{6}$ No caso do Safra Legal, não há o projeto de manejo florestal sustentável, a madeira aproveitada pela indústria é retirada dos lotes dos assentados ou colonos antes da abertura da floresta para a implantação das atividades agrícolas.
Maflops proporciona às famílias assentadas a obtenção do título da terra, uma rede de estradas, planos de manejo florestal para cada propriedade e uma média de US\$ 1.500 pela venda de parte de sua madeira à empresa (Lima et al., 2003, p.71).

Como contrapartida, os assentados (individualmente ou em associações) cedem à Maflops o direito da exploração da madeira existente em seus lotes, segundo o acordo sobre o preço previamente estabelecido. Após a realização dessa exploração - conforme os parâmetros definidos pelo Plano de Manejo Florestal Sustentável (PMFS) -, a Maflops vende a madeira a indústrias localizadas na cidade Santarém (PA). Ou seja, essa empresa funciona exatamente como seu nome indica, prestando serviços (contato com os assentados, encaminhamento da documentação necessária ao PMFS) e realizando o manejo florestal, para, em seguida, repassar a madeira extraída a indústrias situadas acima, na cadeia produtiva do beneficiamento da madeira (serrarias, laminadoras, etc.).

De acordo com os proponentes desse modelo de organização da atividade madeireira na Amazônia, suas vantagens estão relacionadas com a incapacidade governamental de assegurar a governança da indústria madeireira, possibilitando, ao mesmo tempo, o aproveitamento de "estruturas das relações existentes para delegar as responsabilidades que têm dificuldade em executar por deficiências técnicas ou financeiras" (Lima et al., 2003, p.86). Nesse modelo de governança, caberia ao Estado um papel auxiliar, suplementando a "fiscalização privada".

Em um primeiro momento, essa proposição de governança da atividade florestal ganhou repercussão e influenciou o desenvolvimento de experiências similares. É o caso, por exemplo, da empresa Curuatinga, que atua na região de Maués (AM) e processa madeira oriunda do manejo florestal realizado em terras de pequenos produtores, com a intermediação de três empresas, que se responsabilizam pela organização das associações comunitárias, pela elaboração do PMFS e pela própria exploração florestal (Projeto Floresta em Pé, 2007), ou das dezesseis experiências que foram pesquisadas pelo estudo "Análise de acordos en- 
tre empresas e comunidades para a exploração de madeira em assentamentos rurais na região da BR163 e entorno, no estado do Pará" (Amaral Neto; Carneiro; Miranda, 2011).

Entretanto, denúncias de que esse tipo de associação entre empresas e assentados teria dado origem a uma indústria de criação de assentamentos de reforma agrária somente para viabilizar a exploração madeireira na região de Santarém (PA) (GREENPEACE, 2007) provocaram a intervenção do Ministério Público Federal, que entrou na justiça solicitando o cancelamento das portarias de criação de 106 assentamentos pela SR-30 do Instituto Nacional de Colonização e Reforma Agrária (INCRA) (Santana, 2010). Como reação a essas críticas, o INCRA passou a adotar uma atitude mais efetiva nesse processo e elaborou uma Instrução Normativa $^{7}$ para regular as atividades de manejo florestal sustentável em projetos de assentamento.

Nesse novo contexto, a direção regional do INCRA na região de Santarém (PA) passa a questionar a validade da relação de parceria entre empresas e comunidades para a realização de atividades de manejo florestal, como ficou destacado em depoimento do ex-superintendente da SR-30, em evento realizado para avaliar as relações entre empresas, governo e comunidades na região do Baixo Amazonas e da BR-163 (Amaral Neto; Carneiro; Miranda, 2010).

O objetivo da Instrução Normativa do INCRA (n. ${ }^{\circ} 65$, de 27 de dezembro de 2010) é: "padronizar os procedimentos administrativos e a instrução processual das solicitações de autorização de manejo florestal em Projetos de Assentamento de Reforma Agrária” (Carneiro et al., 2011, p.296). nos assentamentos, o importante é destacar que estamos diante de uma nova postura do Estado brasileiro em relação à exploração florestal em assentamentos de reforma agrária (Carneiro et al., 2011).

\section{A Lei de Gestão das Florestas Públicas e o dispositivo das concessões florestais}

Resolver a principal dificuldade apontada pelos empresários do setor florestal na Amazônia para o desenvolvimento da atividade madeireira o acesso seguro à matéria-prima florestal - foi 0 objetivo que levou o governo a propor a aprovação da Lei de Gestão das Florestas Públicas, também conhecida como Lei das Concessões Florestais (Adeodato et al., 2011; Azevedo; Tocantins, 2006).

Nessa perspectiva, a operacionalização da LGFP permitirá a exploração de recursos madeireiros em terras com a situação jurídica plenamente definida, eliminando o principal obstáculo para a modernização da atuação da indústria florestal na região, conforme desejado pelo empresariado do setor florestal (Barreto; Arima, 2002).

A concessão florestal é uma modalidade de contrato pelo qual um usuário privado recebe o direito de exploração do recurso florestal em terras de domínio público, em troca do pagamento de uma taxa pelo aproveitamento desse recurso (Karsenty, 2002). Ao contrário do que é propagado pelos críticos dessa forma de governança da exploração florestal, a concessão não implica a privatização das terras ou florestas públicas da Amazônia; muito pelo contrário, ela representa uma retomada da atuação estatal no fomento da atividade florestal (Carneiro, 2011).

Com a edição da LGFP, o governo federal passa a definir áreas com vocação para a atividade florestal que deverão ser exploradas por meio do manejo florestal sustentável, repassando-as - mediante licitação - para um usuário, que pode ser uma empresa florestal, uma cooperativa ou uma comunidade. Para vencer a licitação, o concessionário terá de demonstrar capacidade para explorar a área, cumprindo os requisitos estabelecidos no 
edital que organiza o processo de concessão, como estabelece sua definição no artigo $3^{\circ}$, item VII, da Lei n. ${ }^{\circ} 11.284$ :

Concessão florestal é a delegação onerosa, feita pelo poder concedente, do direito de praticar manejo florestal sustentável para exploração numa unidade de manejo, mediante licitação, à pessoa jurídica, em consórcio ou não, que atenda às exigências do respectivo edital de licitação e demonstre capacidade para seu desempenho, por sua conta e risco e por prazo determinado.

A operacionalização da política de concessão pode tomar diferentes formatos, com o pagamento sendo realizado por superfície ou por volume explorado, mediante diferentes mecanismos financeiros (Karsenty, 2002). No caso brasileiro, optou-se pela modalidade de concessão em que as empresas devem fazer "uma oferta de preço pelo estoque de madeira presente em cada área a ser concedida", a partir de uma tabela de preços mínimos por espécie florestal a ser explorada, conforme estabelecido pelo Serviço Florestal Brasileiro (SFB) (Drigo, 2010, p. 149). Outra singularidade do processo de concessão no Brasil é o estabelecimento de um mix de critérios econômicos e técnicos para a escolha da proposta vencedora nas licitações, que deve ser aquela que apresente "melhor preço, menor impacto ambiental, maior benefício socioeconômico, maior eficiência e maior agregação de valor local" (Azevedo; Tocantins, 2006, p.15).

Para efetivar a política de concessões, o governo brasileiro criou também uma instituição específica-o Serviço Florestal Brasileiro (SFB) -, vinculada ao Ministério do Meio Ambiente, a quem cabe a tarefa de identificar e gerenciar as florestas públicas do país. ${ }^{8}$ Anualmente, o SFB deve publicar um Relatório de Gestão e um Plano Anual de Outorga Florestal (PAOF). Enquanto o Relatório de Gestão descreve as atividades realizadas, o PAOF apresenta uma projeção do que será desenvolvido no ano seguinte, com destaque para as áreas selecionadas para a realização dos editais de concessão.

${ }^{8}$ Nas unidades subnacionais, esse processo é realizado por órgãos especificamente criados para a execução da política florestal, caso do Instituto de Desenvolvimento Florestal do Estado do Pará (IDEFLOR) e da Secretaria Estadual de Florestas (SEF) no Acre (Adeodato et al., 2011).
Um dos elementos mais importantes do funcionamento do dispositivo das concessões diz respeito ao monitoramento da execução dos contratos, pois é por meio desse mecanismo que será atestada a qualidade do processo de exploração florestal. Tal como foi concebido, o processo de monitoramento das concessões implica a atuação de agências de governo (SFB, IBAMA e Instituto Chico Mendes de Conservação da Biodiversidade (ICMBio) e de uma Auditoria Florestal Independente (AFI) ${ }^{9}$ (Fanzeres, 2011).

Apesar das expectativas geradas pela aprovação da LGFP, o processo de implantação das concessões avança a passos lentos, pois, até o final de 2011, a atividade de exploração florestal havia sido iniciada em apenas duas concessões federais, na Floresta Nacional do Jamari (98.350 hectares), localizada no estado de Rondônia, e na Floresta Nacional de Saraquá-Taquera (140.540 hectares), situada no estado do Pará. A concessão da Floresta Nacional do Amanã (210.161,5 hectares) foi realizada em abril de 2011, mas, como as empresas vencedoras não apresentaram as garantias necessárias para iniciar o processo de concessão, ${ }^{10} \mathrm{ela}$ foi posteriormente revogada (cf. Diário Oficial da União n. ${ }^{\circ} 188$, de 29 de setembro de 2011).

Para o ano de 2012, o PAOF - elaborado pelo Serviço Florestal - identificou dez florestas públicas federais passíveis de concessão, com uma área de manejo florestal empresarial estimada em 2,8 milhões de hectares (Brasil, 2011b). Contudo, informações constantes na página do SFB na internet indicam que a concorrência para as concessões devem concentrar-se em cinco áreas: Floresta Nacional do Crepori (PA), Floresta Nacional de Altamira (PA), Floresta Nacional de Jacundá(RO), Lote Sul da Floresta Nacional de Saraquá-Taquera (PA) e Lote 2 da Floresta Nacional do Amanã.

${ }^{9}$ Essa AFI deverá funcionar como um mecanismo independente de avaliação do cumprimento do contrato de concessão, motivo pelo qual ela será conduzida por uma terceira parte, o Instituto Nacional de Metrologia, Normalização e Qualidade Industrial (INMETRO), que, para tanto, elaborou uma norma para a realização da auditoria (Portaria INMETRO n. ${ }^{\circ} 56$, de 25 de fevereiro de 2010) e para a acreditação das instituições que poderão realizar a AFI.

${ }^{10}$ De acordo com o SFB, o valor dessa garantia "equivale a um ano de produção da unidade de manejo florestal" (Brasil. Ministério do Meio Ambiente, 2011a). 
Devemos, porém, ressaltar que os números apresentados no PAOF merecem ser interpretados com bastante cautela, uma vez que se trata de uma projeção, e o processo de operacionalização das concessões é bastante complexo, incluindo diversas disputas jurídicas sobre as áreas que podem ser efetivamente exploradas (casos em que comunidades e o Ministério Público questionam o SFB) (Castro; Nascimento; Corrêa, no prelo) e sobre o processo de concessão (questionamento das empresas concorrentes), o que torna difícil a definição da área total que deverá estar sendo explorada ao final de cada ano.

\section{UMA TIPOLOGIA DAS DIFERENTES FORMAS DE GOVERNANÇA DA EXPLORAÇÃO FLO- RESTAL NA AMAZÔNIA BRASILEIRA}

Como destaquei nas seções anteriores, ao longo dos últimos vinte anos, foram apresentadas diversas propostas para enfrentar o desafio da promoção de uma gestão sustentável da atividade de produção madeireira na Amazônia. Defendidas por diferentes entidades da sociedade civil, organizações não governamentais, instituições multilaterais e agências estatais, essas propostas podem ser mais bem compreendidas quando inseridas no debate mais amplo sobre as diferentes formas de governança dos recursos naturais, tomando como referência a discussão sobre o papel a ser desempenhado por Estado, mercado e sociedade civil nesse processo.

Meu ponto de partida é a apresenta-

Quadro 1 - Tipologia das formas possíveis de governança florestal

\begin{tabular}{|c|c|c|c|}
\hline \multicolumn{2}{|c|}{} & \multicolumn{2}{|c|}{$\begin{array}{c}\text { Modo de coordenação e } \\
\text { de distribuição de poder }\end{array}$} \\
\cline { 2 - 4 } & Interesse & Merizontal & Vertical \\
\hline \multirow{2}{*}{ Motivo da ação } & Altruísmo/Obrigação & $\begin{array}{l}\text { Comunidade/ } \\
\text { Sociedade civil }\end{array}$ & Estado \\
\cline { 2 - 4 } & &
\end{tabular}

Fonte: Boyer (2004, p. 92).

Quadro 2 - Principais formas de governança da atividade florestal

\begin{tabular}{|c|c|c|c|}
\hline \multicolumn{2}{|c|}{ na Amazônia brasileira } & \multicolumn{2}{c|}{ Modo de coordenação } \\
\cline { 3 - 4 } & Horizontal & Vertical \\
\hline \multirow{3}{*}{$\begin{array}{c}\text { Motivo da } \\
\text { ação }\end{array}$} & Interesse (preço) & $\begin{array}{c}\text { Mercado } \\
\text { tradicional }\end{array}$ & $\begin{array}{c}\text { Florestas } \\
\text { familiares }\end{array}$ \\
\cline { 2 - 4 } & $\begin{array}{c}\text { Interesse } \\
\text { (qualidade)/obrigação }\end{array}$ & $\begin{array}{c}\text { Certificação } \\
\text { florestal }\end{array}$ & $\begin{array}{c}\text { Concessões } \\
\text { florestais }\end{array}$ \\
\hline
\end{tabular}
ção de um quadro no qual exponho, com base em dois critérios (forma de coordenação e motivo da ação dos atores), um conjunto de quatro alternativas que estabelecem os tipos básicos possíveis de governança da atividade florestal (Quadro 1). Esses quatro tipos possíveis de governança correspondem às principais formas de coordenação das atividades econômicas, conforme definido por

Boyer ${ }^{11}$ (2004), e, como mostraremos em seguida(Quadro 2), possuem forte correspondência com as propostas de governança da atividade florestal descritas neste artigo.

No eixo relativo ao tipo de coordenação e distribuição do poder, mantenho a tipologia apresentada por Boyer (2004) inalterada, considerando o mercado e a comunidade como formas de coordenação horizontal, enquanto a firma e o Estado caracterizam-se por uma relação hierárquica, portanto vertical, entre os atores. Entretanto, quando passo para o eixo dos motivos da ação, introduzo uma modificação no modelo original, eliminando a ação movida pelo altruísmo, ${ }^{12}$ para colocar, em seu lugar, um tipo de ação que identifico como movida pelo interesse-qualidade, compreendida como antípoda à ação movida pelo interesse-preço, que é característica do mercado tradicional de comercialização de madeiras tropicais.

Ao estabelecer a diferenciação entre dois tipos de interesse presentes na coordenação das . 
ações (interesse-preço versus interesse-qualidade) relativas às diferentes modalidades de governança da atividade florestal, introduzo a discussão proposta pela economia das convenções sobre o papel desempenhado pelas convenções na coordenação de atores tendo em vista a produção e a comercialização de um produto, nos termos propostos por Salais e Storper (1993):

Uma convenção é um sistema de expectativas recíprocas referidas às competências e aos comportamentos de outros. Essas convenções são relativas à atividade de trabalho (de produção) e à atividade de troca. Para diferentes mundos possíveis, diferentes convenções são passiveis de associação (p.13)

Segundo a interpretação que proponho, a ação movida pelo interesse-qualidade tem sua origem na definição de uma convenção de qualidade (Eymard-Duvernay, 2003), que procura estabelecer parâmetros de sustentabilidade a serem alcançados por produtores florestais e reconhecidos pelos consumidores. Uma vez definidos, esses parâmetros são objetivados no estabelecimento do dispositivo que permite a operacionalização do selo verde (FSC). Essa convenção de qualidade é que permite a coordenação dos atores ${ }^{13}$ no mercado de madeiras certificadas. ${ }^{14}$

O primeiro tipo de modelo de governança pode ser assimilado ao funcionamento atual da maior parte da atividade florestal na Amazônia, aqui denominado "mercado tradicional". Esse mercado envolve a maior parte das 2.227 unidades industriais que extraem e processam madeira na Amazônia (Pereira et al., 2010). Uma descrição desse tipo de mercado encontra-se no estudo Acertando o Alvo 2 (Sobral et al., 2002), que analisou a estrutura de comercialização da madeira oriunda da floresta amazônica no estado de São Paulo. Como

${ }^{13}$ Vale destacar que a economia das convenções não trabalha com o conceito de governança, considerado como tributário de uma visão que aceita a fragilização do Estado no processo de construção da União Europeia (Eymard-Duvernay et al., 2006).

${ }^{14}$ Salais e Storper (1993) propõem uma tipologia de formas de coordenação econômica para analisar os diferentes mundos possíveis de produção. Essa tipologia é organizada com base em dois critérios convencionais: a natureza do produto (genérico ou específico) e a característica da atividade de produção (especializada ou padronizada). demonstra o estudo, a maior parte da madeira consumida passa por depósitos de madeira (69\%), vindo, em seguida, as indústrias de produtos da madeira (21\%) e a construção civil vertical (10\%). No principal segmento de comercialização da madeira amazônica (os depósitos), o interesse verificado pela certificação foi mínimo, e a possibilidade de testar a venda desse tipo de produto foi condicionada ao não aumento do preço. ${ }^{15}$

Nesse tipo de governança, o móvel principal que permite a coordenação dos atores no mercado é o preço, como definido na teoria econômica standard, ou, como aponta a economia das convenções, o preço é o elemento central na definição da convenção constitutiva que organiza esse tipo de intercâmbio (Eymard-Duvernay, 2003). Vale destacar que essa primazia do preço ${ }^{16}$ não implica dizer que outros elementos relativos à qualidade do produto adquirido (madeira tropical) não sejam levados em consideração - Sobral e colaboradores (2002) citam a durabilidade, a resistência e a diversidade de cores como fatores importantes no consumo da madeira amazônica -, mas, tão somente, que o preço é a variável-chave na decisão desses consumidores.

A certificação florestal corresponde ao tipo de governança caracterizada pelo interesse (qualidade) como motivo da ação e por uma forma de coordenação horizontal. Como indiquei na seção 2.1, ela corresponde a um pequeno conjunto de empresas que exploram, atualmente, 1.146,9 mil hectares de florestas (Pereira et al., 2010). A definição do interesse (qualidade) como motivo da ação dos atores envolvidos nessa forma de governança difere do esquema original proposto por Boyer (2004), que identifica o altruísmo como motivação

15 Segundo o estudo, 80\% dos entrevistados nunca tinham ouvido falar da certificação. Quando esclarecidos sobre o assunto, $40 \%$ revelaram não ter nenhum interesse no tema, e os demais só se interessariam se isso não implicasse aumento no preço da madeira (Sobral et al., 2002).

${ }^{16} \mathrm{O}$ argumento de que a troca mediada pelo preço - a transação mercantil básica da abordagem econômica convencional - implica também o estabelecimento de uma convenção de qualidade é uma das diferenças que os autores da economia das convenções estabelecem com outras abordagens que destacam a dimensão da qualidade nos processos de intercâmbio mercantil (EymardDuvernay, 2009). 
para a ação. Operamos essa mudança porque achamos importante diferenciar o mercado tradicional - que funciona tendo o preço como principal parâmetro de coordenação entre os atores - do mercado de madeiras certificadas, que tem, na convenção de qualidade relativa ao caráter sustentável do processo de exploração florestal, seu elemento central (Carneiro, 2004).

Importa ressaltar que a caracterização da distribuição do poder, nessa forma de governança como horizontal, não significa a inexistência de assimetrias entre os diversos integrantes desse mercado, ${ }^{17}$ pois, como vários estudos mostram, existem atores que desempenham um papel central no mercado de madeiras certificadas (Carneiro, 2004), mas, tão somente, que a coordenação econômica é realizada por meio da relação entre um conjunto de atores (produtores, intermediários, consumidores), mediada pela construção de uma convenção de qualidade (o selo do FSC).

A forma de governança identificada com o modelo das florestas familiares corresponde, em nossa tipologia, à forma de coordenação realizada pela firma. Nesse tipo de governança, o principal motivo da ação é o interesse, e a distribuição do poder é vertical. Embora a proposta originalmente apresentada buscasse fortalecer os produtores familiares que vivem em assentamentos, por meio do estabelecimento de acordos entre empresas e esses produtores organizados em associações comunitárias (Lima et al., 2003), os estudos realizados sobre a operação do modelo mostraram que ele tende a privilegiar empresas que se especializam na prestação de serviços e na exploração madeireira nos assentamentos (Amaral Neto et al., 2011). Nesse sentido, o modelo acaba funcionando como se as empresas florestais processadoras de madeira (serrarias, laminadoras, fábricas de compensa-

17 Uma das principais críticas feitas à abordagem convencionalista refere-se à minimização do conflito e das relações assimétricas que permeiam esses acordos (Amable; Palombarini, 2005). Contudo, diversos autores convencionalistas argumentam que essa teoria não nega a questão da dominação, da assimetria de poder entre as partes de um acordo, mas, que o seu foco direciona-se para o processo de construção de representações comuns (as grandezas) na elaboração de acordos legítimos (Orléan, 2004) e que o conflito é parte constitutiva de processos de cooperação (Salais, 2003). dos) terceirizassem essa parte de sua atividade, delegando a outras empresas o trabalho de organização da produção madeireira nos assentamentos.

Portanto, nesse caso, temos, não a construção de um acordo entre dois ou mais agentes no mercado, a partir da elaboração de uma representação compartilhada da qualidade do produto em questão, ${ }^{18}$ mas, tão somente, a entrada de uma empresa (terceirizada) nos assentamentos, que, com base em conhecimentos específicos (domínio do processo de legalização da operação de manejo) e nas relações estabelecidas com os assentados e representantes dos órgãos governamentais implicados nesse processo (especialmente o INCRA), consegue viabilizar a exploração madeireira por meio de projetos de manejo florestal. ${ }^{19}$

Se a coordenação, nesse tipo de governança, é vertical, a motivação dos atores envolvidos nesse modelo não implica o estabelecimento de nenhum tipo de convenção de qualidade que tenha como parâmetro o bom manejo florestal, pois, salvo raríssimas exceções em que o acordo entre empresas e comunidades prevê a certificação florestal (Amaral Neto et al., 2011), o objetivo central das empresas madeireiras é a garantia do abastecimento legalizado da matéria-prima florestal.

Embora esse modelo tenha tido um forte desenvolvimento nos últimos dez anos, garantindo o abastecimento de polos madeireiros importantes, situados no centro e no oeste do estado do Pará (Carneiro et al., 2011), a iniciativa recente do INCRA de normatizar a extração de madeiras em áreas de assentamento tornam o seu futuro bastante incerto, como destaquei na segunda seção deste artigo.

A última forma de governança corresponde ao modelo das concessões florestais. Nela, temos a ${ }^{18} \mathrm{O}$ funcionamento desse dispositivo exige o estabelecimento de uma empresa intermediando o acesso das empresas processadoras de madeira aos recursos florestais, ou seja, estamos diante de uma situação que teoricamente pode ser descrita como a do estabelecimento de uma firma (coordenação vertical) como alternativa ao funcionamento imperfeito do mercado (coordenação horizontal).

${ }^{19}$ Existem algumas situações que escapam a esse tipo de situação, caso, por exemplo, do acordo estabelecido entre a associação do PDS Virola Jatobá com a empresa Vitória Régia Exportadora Ltda. Contudo, como mostra o estudo sobre os acordos (Amaral Neto et al., 2011), esse tipo de acordo é uma honrosa exceção num quadro de inúmeras situações em que os acordos são estabelecidos de forma extremamente adversa para os assentados. 
obrigação como motivo da ação e uma distribuição do poder de natureza vertical. Essa caracterização corresponde ao modelo definido por Boyer (2004, p.91), que entende o Estado como capaz de "organizar relações voluntárias entre indivíduos perseguindo seus interesses e dotados de um poder igual". Os indivíduos, nesse caso, são as empresas (ou cooperativas) que participam das concorrências organizadas pelo SFB para obter as concessões.

Para atingir os objetivos da política de concessões, o SFB definiu um tipo de concorrência que procura valorizar a capacidade efetiva das empresas para realizar a exploração florestal de melhor padrão (técnico e socioambiental), ao mesmo tempo em que criou mecanismos para evitar a concentração econômica, isto é, para impedir que uma empresa venha a concentrar várias áreas de exploração florestal. ${ }^{20}$

De forma semelhante ao que ocorre na certificação florestal (Carneiro, 2011), o funcionamento do dispositivo das concessões pressupõe o estabelecimento de uma convenção de qualidade do processo de exploração florestal, isto é, a madeira a ser produzida deve estar de acordo com um conjunto de especificações definidas no edital de concessão. Para atestar essa convenção de qualidade, o dispositivo prevê além da fiscalização estatal (SFB, IBAMA e ICMBio), o funcionamento de uma auditoria florestal independente, que será paga pela empresa concessionária e realizada por uma terceira parte, não envolvida no processo de concessão.

\section{CONCLUSÃO}

Este artigo teve por objetivo analisar os principais dispositivos de governança da exploração florestal na Amazônia brasileira, submetendo-os a uma leitura orientada por elementos da reflexão da sociologia econômica sobre as formas de coor-

${ }^{20}$ Caso do artigo $3 .^{\circ}$ da Lei Geral das Florestas Públicas, que estabelece a obrigação da licitação de lotes de tamanho diferentes (para atender "pessoas jurídicas de pequeno porte, micro e médias empresas”), e do artigo 77, que estabelece um limite máximo (dez por cento) de áreas de concessão que podem ser detidas por um único proprietário. denação das atividades econômicas, tomando como referência o caráter horizontal ou vertical dessa coordenação, junto com o tipo de motivação dos atores (interesse-preço, interesse-qualidade e obrigação) envolvidos na atividade florestal.

A interpretação desses dispositivos de governança mostrou que a proposta das florestas familiares, apesar de descrita por seus proponentes como uma forma mais justa e democrática de exploração, pois permitiria incorporar a agricultura familiar no processo de exploração florestal, possui muita semelhança com o funcionamento do mercado tradicional de madeiras, uma vez que a mobilização dos atores envolvidos nesse processo não implica a elaboração de nenhuma convenção de qualidade, de forma que o acesso à madeira, nesse tipo de governança, é orientado principalmente pelo fator preço.

A certificação florestal é compreendida como um dispositivo de governança semelhante ao mercado tradicional no que concerne à natureza da coordenação (horizontal), mas difere dele no quesito da motivação dos atores. Nesse dispositivo de governança, é orientada pelo estabelecimento de uma convenção de qualidade cujo principal parâmetro é o estabelecimento de normas que procuram tornar a exploração florestal mais sustentável em termos ambientais e sociais.

O último dispositivo de governança analisado é o das concessões florestais. À diferença dos demais, esse dispositivo tem como principal ator o Estado, cuja atuação decorre da obrigação de promover o desenvolvimento da economia florestal na região. Entretanto, de forma semelhante à certificação, esse dispositivo caracteriza-se pelo estabelecimento de uma convenção de qualidade, que deve nortear sua relação com as empresas que venham a obter as concessões.

Uma das características mais interessantes da política de concessões é que ela pode ser considerada um instrumento de ação pública (Lascoumes; Le Galès, 2004) de tipo híbrido, implicando a criação de uma agência estatal (SFB) e a articulação de outras agências para sua operacionalização (ICMBio e IBAMA), mas incorporando, também, dispositi- 
vos de fiscalização e monitoramento oriundos da experiência da certificação florestal (Carneiro, 2011), cuja lógica de funcionamento está associada à participação de grupos da sociedade civil e à utilização de estímulos mercantis (sobrepreço, acesso a mercados) de forma a premiar as empresas que enveredam pela chamada boa gestão florestal.

Como argumentei em outro artigo (Carneiro, 2011), a política de concessões deve estabelecer-se como a forma predominante do funcionamento da exploração florestal (de mata nativa) na Amazônia, pois resolve o principal problema identificado por empresários e experts florestais para esse tipo de atividade econômica na região: a insegurança fundiária. Entretanto, as informações mais recentes sobre o desenvolvimento desse processo mostram que ele se desenrola num ritmo lento, como ocorre em períodos de transição, característicos de situações marcadas pelo estabelecimento de um novo quadro institucional (Costa, 2007), quando as formas pretéritas de organização da atividade econômica mostram que ainda possuem pertinência e as novas formas lutam para estabelecer sua viabilidade.

(Recebido para publicação em 22 de outubro de 2011) (Aceito em 17 de fevereiro de 2012)

\section{REFERÊNCIAS}

ADEODATO, Sérgio; MONZONI, Mario; BETIOL, Luciana Stocco; VILLELA, Malu. Madeira de ponta a ponta: o caminho desde a floresta até o consumo. São Paulo: FGV RAE, 2011.

AMABLE, Bruno; PALOMBARINI, Stefano. L'économie politique n'est pas une science morale. Paris: Raisons d'Agir, 2005.

AMARAL, Paulo; AMARAL NETO, Manuel. Manejo florestal comunitário na Amazônia brasileira: situação atual, desafios e perspectivas. Brasília, DF: IEB, 2000.

AMARAL NETO, Manuel; CARNEIRO, Marcelo Domingos Sampaio; MIRANDA, Katiuscia Fernandes (Org.) Análise dos acordos entre empresas e comunidades para a exploração florestal madeireira em assentamentos rurais na região da BR 163 e entorno, no Estado do Pará. Belém: IEB, 2011. $97 \mathrm{p}$.

AZEVEDO, Tasso Rezende de; TOCANTINS, Maria Alice C. Instrumentos econômicos da nova proposta para a gestão de florestas públicas no Brasil. Megadiversidade Belo Horizonte, v.2, n.1-2, p. 13-17, dez. 2006.
BARON, Catherine. La gouvernance: débats autour d'un concept polysémique. Revue Droit et Société, Paris, n.54, p.329-351, 2003

BARRETO, Paulo; ARIMA, Eugênio, Florestas nacionais na Amazônia: consultas a empresários madeireiros e atores afins à política florestal. Brasília, DF: Ministério do Meio Ambiente, 2002

BEUSCART, Jean-Samuel; PEERBAYE, Ashveen. Histoires de dispositifs. Terrains \& Travaux, [S.1.], Mendeley, n. 11, p.3-15, 2006.

BOLTANSKI, Luc. L'amour et la justice comme compétences: trois essais de sociologie de l'action. Paris: Métailié, 1990

BOLTANSKI, Luc; THÉVENOT, Laurent. De la justification les économies de la grandeur. Paris: Galimard, 1991.

BORRAZ, Olivier. Les normes: instruments dépolitisés de l'action publique. In: LASCOUMES, Pierre; LE GALES Patrick (Dir.) Gouverner par les instruments. Paris: Presses de Sciences Po, 2004. p. 123-161

BOYER, Robert. Une théorie du capitalisme est-elle possible? Paris: Odile Jacob, 2004.

L'économie des conventions 15 ans après: un point de vue à partir de la théorie de la régulation. In: EYMARD-DUVERNAY, François (Dir.) L'économie des conventions: méthodes et résultats. Paris: La Découverte, 2006. T. II. p.45-66.

BRASIL. Ministério do Meio Ambiente. Serviço Florestal Brasileiro. Gestão de florestas públicas - Relatório 2010 Brasília, DF: 2011a.

. Plano Anual de Outorga Florestal - 2012. Brasília, DF: $2011 \mathrm{~b}$.

BUCLET, Benjamin. Les expérimentations des ONG en Amazonie: quel pouvoir pour quelle responsabilité? Lusotopie, Paris, n.1, p.263-282, 2002.

. Os peritos não governamentais da biodiversidade amazônica e seus financiadores internacionais: uma parceria desigual em torno de interesses comuns. Revista Pós Ciências Sociais, São Luís, v.6, n.12, p.89-113, 2009.

CARNEIRO, Marcelo Domingos Sampaio. $O$ dinheiro é verde? A construção social do mercado de madeiras certificadas na Amazônia brasileira. 2004. $251 \mathrm{f}$. Tese (Doutorado em Sociologia) - Instituto de Filosofia e Ciências Sociais, Universidade Federal do Rio de Janeiro. 2004.

A construção social do mercado de madeiras certificadas na Amazônia brasileira: a atuação das ONGs ambientalistas e das empresas pioneiras. Sociedade e Estado, Brasília,DF, v.22, n.3, p.681-713, set./dez. 2007.

. Da certificação para as concessões florestais. organizações não governamentais, empresas e a construção de um novo quadro institucional para o desenvolvimento da exploração florestal na Amazônia brasileira. Boletim do Museu Paraense Emílio Goeld: Ciências Humanas, Belém, v.6, n.3, p.525-541, set./dez. 2011.

. Certificação florestal: origens, atores e controvérsias sobre a melhor forma de promover o manejo florestal e combater o desmatamento. In: ; LIMA, João Vicente Ribeiro Barroso da Costa (Org.) Sociedade, florestas e sustentabilidade. Maceió: EDUFAL, 2012. No prelo.

; AMARAL NETO, Manuel; MIRANDA, Katiuscia Fernandes (Org.). Relações entre empresas, governos e comunidades na Amazônia brasileira: reflexões e propostas. Belém: Instituto Internacional de Educação do Brasil, 2010.

SABLAYROLLES, Philippe. Polí-

ticas públicas e os desafios para consolidação do MFCF em assentamentos e unidades de conservação na Amazô- 
nia brasileira. In: CRUZ, Hildemberg et al. (Org.) Relação empresa/comunidade no contexto do manejo florestal comunitário e familiar: uma contribuição do projeto Floresta em Pé. Belém: IBAMA, 2011. p.286-306.

CASTRO, Edna Maria Ramos de; NASCIMENTO, Sabrina Mesquita do; CORRÊA, Simy de Almeida. Política florestal e empresas do setor madeireiro: o que há de novo em suas estratégias? Revista Pós Ciências Sociais, São Luís, . No prelo.

COCHOY, Franck. Une sociologie du packaging, ou l'âne de Buridan face au marché. Paris: PUF, 2002. 225 p.

COMMAILLE, Jacques; JOBERT, Bruno. La régulation politique: l'émergence d'un nouveau régime de connaisance? In: Les métamorphoses de la régulation politique. Paris: LGDJ, 1998. p. 11-32.

CEE. Commission Économique des Nations Unies pour L'Europe; FAO. Organisation des Nations Unies pour L'Alimentation et L'Agriculture. Revue Anuelle du Marché des Produits Forestiers 2007-2008. New York et Genève: 2009.

COSTA, Francisco de Assis. A questão agrária na Amazônia e os desafios estratégicos de um novo desenvolvimento. In: BECKER, Bertha; ALVES, Diogenes Salas; COSTA, Wanderley Messias da (Org.) Dimensões humanas da biosfera-atmosfera na Amazônia. São Paulo: EDUSP, 2007. p.129-166.

DEZALAY, Yves. De la défense de l'environnement au développement durable: l'émergence d'un champ d'expertise des politiques européennes. Actes de la Recherche en Sciences Sociales, Paris, n.1-2, p.67-80, 2007.

DRIGO, Isabel Garcia. As barreiras para a implantação de concessões florestais na América do Sul: os casos de Bolívia e Brasil. 2010. 287 f. Tese (Doutorado em Ciência Ambiental) - Programa de Pós-Graduação em Ciência Ambiental, Universidade de São Paulo, São Paulo, 2010.

EYMARD-DUVERNAY, François. La négociation de la qualité. In: NICOLAS, François; VALCESCHINI, Egizio. Agro-alimentaire: une économie de la qualité. Paris: INRA: Economica, 1995. p.39-48.

Du marché généralisé à la pluralité des conventions constitutives. Cahiers Lilois d'Économie et Sociologie, n. 41-42, p. 15-32, déc. 2003.

. L'économie des conventions entre économie et sociologie: l'homme conventionalis calcule et parle. In: STEINER, Philippe; VATIN, François (Dir.) Traité de sociologie économique. Paris: PUF, 2009. p. 131-164.

EYMARD-DUVERNAY, François; FAVERAU, Olivier; ORLÉAN, André; SALAIS, Robert; THÉVENOT, Laurent. Des contrats incitatifs aux conventions légitimes: une alternative aux politiques néolibérales. In: (Dir.) L'économie des conventions: méthodes et résultats. Paris: La Découverte, 2006. T.II, p.17-42.

FANZERES, Anna. Auditorias florestais independentes nas concessões florestais. Rio de Janeiro, maio 2011. Apresentação em Power Point.

FAVERAU, Olivier. Conventions et régulation. In: BOYER, Robert; SAILLARD, Yves (Dir.) Théorie de la régulation: l'état des savoirs. Paris: La Découverte, 2002. p. 511-520.

GOMES, Lucinaldo S. O programa Safra Legal na Transamazônica: um novo uso dos recursos florestais nos assentamentos? 2005. Monografia (Curso de Licenciatura Plena em Ciências Agrárias) - Programa Agricultura Familiar, Universidade Federal do Pará, campus de Altamira, 2005.

GREENPEACE. Campanha Amazônia. Assentamentos de papel, madeira de lei. Relatório Denúncia. Parceria entre Incra e madeireiros ameaça a Amazônia. 20 ago. 2007. 30 p. Disponível em: www.greenpeace.org/brasil/pt. Acesso em: 10 mar. 2010.
GUENEAU, Stéphane; TOZZI, Pascal. Towards the privatization of global forest governance? International Forestry Review, Oxford, INASP, v.10, n.3, p.550-562, 2008.

JOBERT, Bruno. Le mythe de la gouvernance dépolitisée. In: FAVRE, Pierre et al. (Org.) Etre gouverné: études en l'honneur de Jean Leca. Paris: Presses de Sciences Po, 2003. p.273-285.

KARPIK, Lucien. L'économie des singularités. Paris: Gallimard, 2007.

KARSENTY, Alain. Fiscalité et gestion des forêts tropicales. Cahiers d'Économie et Sociologie Rurales, Paris, INRA, n.64, p.6-36, 2002.

LASCOUMES, Pierre; LE GALÈS, Patrick. Introduction: l'action publique saisie par ses intruments. In: (Dir.) Gouverner par les instruments. Paris: Presses de Sciences Po, 2004. p.11-44.

LE GALÈS, Patrick. Les réseaux d'action publique entre outil passe-partout et théorie de moyenne portée. In: ; THATCHER, Marc (Dir.) Les réseaux de politique publique: débat autour des policy networks. Paris: L'Harmattan, 1995. p.13-28.

Régulation, gouvernance et territoire. In: COMMAILLE, Jacques; JOBERT, Bruno (Dir.) Les métamorphoses de la régulation politique. Paris: LGDJ, 1998. p. 203-240.

LIMA, Eirivelthon et al. Florestas familiares: um pacto sócio-ambiental entre a indústria madeireira e a agricultura familiar na Amazônia. Belém: IPAM, 2003.

MICHELETTI, Michele. Le consumérisme politique: une nouvelle forme de gouvernance transnationale? Sciences de la Société, Paris, CNRS, n.62, p.119-144, 2004.

NEPSTAD, Daniel et al. Governando a indústria madeireira na Amazônia. In: ZARIN, Daniel et al. (Org.) As florestas produtivas nos neotrópicos: conservação por meio do manejo sustentável? São Paulo: Peirópolis; Brasília, DF: IEB, 2005. p.481-511.

ORLÉAN, André. L'économie des conventions: définitions et résultats. In: (Dir.) Analyse économique des conventions. 2.éd. Paris: PUF, 2004. p.9-48.

PEREIRA, Denys; SANTOS, Daniel; VEDOVETO, Mariana; GUIMARAES, Jayne; VERISSIMO, Adalberto. Fatos florestais da Amazônia 2010. Belém: Imazon, 2010. PROJETO FLORESTA EM PÉ. Relatório Cadeias Produtivas Madeireiras na Região de Santarém - Versão 11 out. 2007. Santarém, 2007.

SALAIS, Robert. Postface. In: STANZIANI, Alessandro (Dir.) La qualité des produits alimentaires en France (XVIII ${ }^{e}-X X^{e}$ siècles). Paris: Belin, 2003. p.271-290.

STORPER, Michael. Les mondes de production: enquête sur l'identité économique de la France. Paris: Éditions de L'EHESS, 1993. Partie I, p.22-98.

SANTANA, Raimundo Rodrigues. Justiça ambiental na Amazônia: análise de casos emblemáticos. Curitiba: Juruá Editora, 2010.

SILVA, José Natalino Macedo. Manejo florestal. Belém: Embrapa Amazônia Oriental; Brasília,DF: Embrapa Informação Tecnológica, 2001.

SMOUTS, Marie-Claude. Forêts tropicales, jungle internationale: les revers de l'écopolitique mondiale. Paris: Presses de Sciences Po, 2001.

SOBRAL, Leonardo et al. Acertando o alvo 2: o consumo de madeira amazônica e a certificação florestal no estado de São Paulo. Belém: Imazon, 2002. 


\section{BETWEEN STATE, SOCIETY AND THE MARKET: an analysis of the forest industry's governance devices in the Amazon}

\section{Marcelo Domingos Sampaio Carneiro}

The debate on the most efficient devices to cope with environmental problems usually focuses on two opposing forms of regulation: on one side, the actions based on governmental initiatives, the so-called "command and control actions", and, on the other side, those based on market mechanisms and civic initiatives aiming to constraint the aforesaid actions, such as the codes of good practice adopted by many companies. The present article discusses three regulation devices used by the forest industry in the Amazon - the forest certification, the family forest models and the forest concession policies - in order to highlight their major differences. The discussion is based on Boyer's typology of mechanisms for economic coordination (2004), enriched by a study on Economics of Convention, that classifies the forms of coordination of actors according to the nature of the main constitutive convention.

KEY-WORDS: forest industry, governance, public policies, economic sociology.

\section{ÉTAT, SOCIÉTÉ ET MARCHÉ: l'analyse des dispositifs de gouvernance de l'industrie forestière en Amazonie}

\section{Marcelo Domingos Sampaio Carneiro}

Dans la discussion portant sur les outils les plus efficaces capables de traiter et de corriger les problèmes d'environnement, deux formes basiques de réglementation s'opposent: d'une part, les actions fondées sur l'initiative de l'état appelées "commande et contrôle", d'autre part, les réalisations effectuées par l'intermédiaire des mécanismes de marché et sur l'initiative de groupes autonomes de limitation des actions, groupes guidés par la notion de civisme, comme c'est dans le cas des codes de bonne conduite adoptés par certaines entreprises. Nous présentons dans cet article trois des différents dispositifs de réglementation de l'industrie forestière en Amazonie - la certification forestière, le modèle des forêts familiales et la politique des concessions forestières - en essayant de mettre en évidence leurs principales différences. Nous nous basons sur une tipologie des formes générales de coordination des activités économiques proposée par Boyer (2004), enrichie par une contribution de l'économie des conventions qui classe le type de coordination entre acteurs en fonction de la nature de la convention constitutive prédominante.

MoTS-CLÉS: industrie forestière, gouvernance, politiques publiques, sociologie économique.

Marcelo Domingos Sampaio Carneiro - Doutor em Sociologia pela Universidade Federal do Rio de Janeiro, com estágio na École de Hautes Études en Sciences Sociales (França). Professor Adjunto do Programa de Pósgraduação em Ciências Sociais da Universidade Federal do Maranhão. Publicou recentemente (em coautoria) os livros: A terceira margem do rio: ensaios sobre a realidade do Maranhão no novo milênio (EDUFMA, 2009); A agricultura familiar da soja na região sul e o monocultivo no Maranhão (FASE, 2008) e os artigos: Crítica social e responsabilização empresarial. Análise das estratégias para a legitimação da produção siderúrgica na Amazônia Oriental. Caderno CRH, v. 21, n. 53, maio/ago. 2008; Da certificação para as concessões florestais. Ongs, empresas e a construção de um novo quadro institucional para o desenvolvimento da exploração florestal na Amazônia Brasileira, Boletim do MPEG, 2011. 